\title{
PEDAGOGIA EM AMBIENTE NÃO-ESCOLAR: A ATUAÇÃO DO PEDAGOGO NO TRIBUNAL DE JUSTIÇA DO PARÁ.
}

\author{
Gilmar Pereira da SILVA \\ Campus Universitário de CametáUJPA \\ gpsilva@ufpa.br \\ Riane Conceição Ferreira FREITAS \\ Tribunal de Justiça do Estado do Pará \\ rianecffreitas@hotmail.com
}

Resumo: O presente trabalho é parte da pesquisa "A regulamentação do curso de pedagogia e a atuação do pedagogo no Judiciário". Ele remete à ânsia em tematizar as construções teóricas recentes na área da investigação em educação, na qual o exercício profissional do pedagogo extrapola os liames da docência e se insere em áreas que vão além dos recursos humanos das empresas ou de ações inseridas em projetos e programas, quase sempre com modalidades de cunho formativo, lúdico e recreativo. As breves observações a respeito das políticas públicas educacionais que regulamentam o curso de pedagogia e a consequente formação das instituições de educação superiores visam a estabelecer um debate sobre as transformações no mundo do trabalho envolvendo o profissional da pedagogia, enfocando a atuação do pedagogo no Poder Judiciário. Assumimos o materialismo dialético como principal referência para a nossa pesquisa e utilizamos os procedimentos característicos da pesquisa qualitativa.

Palavras-chave: Regulamentação. Formação. Atuação.

Abstract: This work is part of the research "The regulation of the pedagogy course and the work of pedagogues in the judiciary" and refers to the longing in focusing on recent theoretical constructions in the area of research in education in which the exercise of professional educator goes beyond the bonds of teaching and the resources of the enterprises or shares included in projects and programs, often with arrangements for formative nature, leisure and recreation. The brief remarks about the public education policies that regulate pedagogy courses and the consequent formation of institutions of higher education seek to establish a discussion about the transformations in work involving the pedagogy professional, focusing on the work of pedagogues in the Judiciary. We assume dialectical materialism as the main reference for our research and utilize the procedures typical of qualitative research.

Key-Words: Regulation. Formation. Practice. 


\section{Introdução}

O presente trabalho, que faz parte de uma pesquisa em andamento da Pós-Graduação em Educação da Universidade Federal do Pará e está inserida no Grupo de Pesquisa sobre Trabalho e Educação - GEPTE, visa levantar alguns aspectos sobre a atual demanda do pedagogo no mercado de trabalho, visto que ele é o profissional da educação em sentido pleno,

que atua em várias instâncias da prática educativa, direta ou indiretamente ligadas à organização e aos processos de transmissão e assimilação ativa de saberes e modos de ação, tendo em vista objetivos de formação histórica. Em outras palavras, pedagogo é um profissional que lida com fatos, estruturas, contextos, situações, referentes à prática educativa em suas várias modalidades e manifestações (LIBÂNEO, 1996, p. 127).

Nesse sentido, as instituições oficiais e os órgãos responsáveis pelas diretrizes da formação do pedagogo necessitam adaptar-se a novas coordenadas, desconstruindo e reconstruindo sua prática de formação de educadores/educadoras, para adequar-se às novas demandas. Como exemplo dessas demandas, vemos a grande quantidade de concursos públicos que nos últimos anos ofertaram vagas para pedagogos e pedagogas nas mais diversas áreas, em ambientes que não são o escolar, dentre eles, o Poder Judiciário paraense que, em certames ocorridos nos anos de 2006 e 2009, ofertou vagas (convocou, no primeiro, e está em fase de conclusão, no segundo) para: Analista Judiciário - Área/Especialidade Pedagogia, com o objetivo de desempenhar as seguintes funções:

participar de comissões, quando designado, e de treinamentos diversos de interesse da administração; assessorar dirigentes e magistrados, por meio de pareceres técnicos em processos que requeiram conhecimento específico da ciência em apreço; executar individualmente ou em equipe atividades relacionadas com a administração de recursos humanos, desenvolvimento de pessoal, treinamento, estudos, pesquisas, análises organizacionais, planejamento de recursos humanos, serviço social 
aos funcionários e outras tarefas das Unidades Administrativas; bem como desempenhar outras atividades correlatas ou outras atribuições que possam vir a surgir, conforme as necessidades da área ou do Tribunal (EDITAL N. ${ }^{\circ}$ 1/2006 - TJPA, de $1 .^{\circ}$ de marco de 2006, Diário de Justiça do Estado do Pará).

Portanto, refletir sobre as políticas públicas educacionais que regulamentam o curso de pedagogia e a consequente formação das instituições de educação superiores para a atual demanda do mercado de trabalho é tarefa urgente, visto que o atual cenário de formação do pedagogo está basicamente voltado para a formação docente.

Nesse ínterim, realizar a discussão de como a mais recente normatização para o curso de pedagogia pode abranger, nos desenhos curriculares, uma formação do pedagogo que enfoque não "a busca pela produtividade guiada pelo princípio de racionalidade, que se traduz, no empenho em se atingir o máximo de resultados com o mínimo de dispêndio" (SAVIANI apud ARAÚJO, 2007, p. 195), mas, sobretudo, uma formação que vise a constituição de referências para significativas experiências educacionais, associando os processos de formação e de educação profissional com o ideário da emancipação da classe trabalhadora.

Para empreender as análises dos discursos sobre a atuação e a consequente formação, observando as regulamentações dos cursos de pedagogia, recorremos às diretrizes curriculares, por exemplo, do Curso de Pedagogia da Universidade Federal do Pará que, em sua atual formulação legal, destina-se à formação do licenciado para "o exercício da docência na educação infantil e séries iniciais do ensino fundamental, no ensino médio - modalidade normal - nas disciplinas de formação pedagógica, da gestão e coordenação pedagógica de unidades educacionais escolares e não-escolares", definindo como "gestão e coordenação pedagógica as atividades inerentes à Orientação Educacional, à Supervisão Escolar e à Administração Escolar" (Resolução n ${ }^{\circ} 2669 / 99^{1}$ ) e que foi ampliada pela

\footnotetext{
${ }^{1}$ Resolução do Colegiado do Curso de Pedagogia, que altera a Resolução No 1234/86CONSEP e define o Currículo do Curso de Licenciatura Plena em Pedagogia da Universidade Federal do Pará.
} 
Resolução No 1/2006, do Conselho Nacional de Educação/CP, para "os cursos de Educação Profissional na área de serviços e apoio escolar, bem como em outras áreas que sejam previstos conhecimentos pedagógicos", ambas baseada na Lei de Diretrizes e Bases da Educação Nacional L.D.B. (Lei 9394/96) em seu artigo 64:

A formação de profissionais de educação para administração, planejamento, inspeção, supervisão e orientação educacional para a educação básica, será feita em cursos de graduação em pedagogia ou em nível de pós-graduação, a critério da instituição de ensino, garantida, nesta formação, a base comum nacional (grifos nossos).

Há de se notar que a L.D.B. define o pedagogo como 'profissional da educação' e o direciona para a educação básica, que é um nível de ensino, normatizado, na mesma lei, no Art. $21^{\circ}$, inciso I - "educação básica, formada pela educação infantil, ensino fundamental e ensino médio", ou seja, uma formação acadêmica voltada para a escola.

Enfatizar a atuação dos pedagogos em ambientes que não sejam os tradicionais (docência de $1^{\mathrm{a}}$ a $4^{\mathrm{a}}$ série do ensino fundamental, supervisão, administração e orientação educacionais) e discutir a regulamentação desses profissionais em diversas áreas que extrapolam a escolar faz parte da discussão que propomos.

Problematizar a regulamentação com a consequente formação/ atuação dos pedagogos que as instituições de educação superior colocam no mercado de trabalho é pertinente para compreendermos se há um paradoxo entre formação $\mathrm{x}$ inserção no mundo do trabalho, uma vez que as faculdades de educação estão limitando a atuação desses profissionais ao espaço escolar - quando não incluem disciplinas com abrangência de atuação em ambientes não-escolares, mesmo as optativas -, ou ainda não conseguiram compreender a amplitude e responsabilidade que a atuação do profissional da pedagogia possui nos dias atuais.

Discutir as políticas públicas educacionais de regulamentação do curso de pedagogia e, consequentemente, a atuação desses profissionais nas mais diversas áreas não-escolares, especialmente na jurídica, coloca a necessidade de conhecer os mais variados elementos que envolvem a prática educativa e a de compreendê-la de forma mais completa possível. 
No entanto, não se pode fazer isto sem um método, um caminho que permita compreender o fenômeno educativo para "descobrir", nos fenômenos, a categoria mais simples [o empírico] para chegar à categoria síntese de múltiplas determinações [concreto pensado] (PIRES, 1997).

Isto significa dizer que a análise do fenômeno educacional em estudo pode ser empreendida quando conseguimos descobrir sua mais simples manifestação para que, ao nos debruçarmos sobre ela, elaborando abstrações, possamos compreender plenamente o fenômeno observado (p. 87).

Para compreenderas políticas públicas educacionaisque normatizam e regulamentam a atuação do profissional da pedagogia é preciso saber o que temos hoje de leis estabelecidas. Contudo, primeiramente é necessário esclarecer que os conceitos e referenciais teóricos que nos apoiam nessa discussão foram escolhidos porque os autores aqui trabalhados se tornaram fontes consistentes com ferramentas produtivas e

nos convidam a pensar de outra forma o que pensamos, buscando tensionar essas mesmas fontes conceituais, ousando cortejá-las com outras talvez menos seguras [...] e, especialmente, ousando estabelecer relações entre esses referenciais e as primeiras incursões que fazemos em nossos materiais empíricos (FICHER, 2007, p. 58).

Com isso, dar conta da heterogeneidade que é falar em políticas públicas educacionais e enveredar por instituições em suas múltiplas práticas de formação de educadores, requer uma proposta que nos leve a pesquisar, a

pensar e analisar as práticas, [...] aceitar que não destruiremos o grande mal, nem faremos irromper o grande e belo absoluto da total liberação; significa que, modestamente, podemos estar participando de uma reescrita de nós mesmos, do estabelecimento de uma nova prática (FICHER, 2007, p.67) 
Nesse sentido, como ponto de partida, analisaremos as Diretrizes Curriculares para o Curso de Pedagogia, definidas há quatro anos, pela Resolução $n^{\circ}$ 1/2006 do Conselho Nacional de Educação, que trouxeram à tona, mais uma vez, o embate a respeito da identidade do curso e da sua finalidade profissionalizante, agora instituído como licenciatura, o que acaba por acentuar as discussões entre duas vertentes ideológicas, isto é: uma que assinala a Pedagogia como sistema nacional de profissionais da educação que extrapolam os liames da docência (LIBÂNEO, 2006; PIMENTA, 2006; FRANCO, 2006) e a outra que adota a "docência como a base da formação profissional de todos aqueles que se dedicam ao estudo do trabalho pedagógico" (ANFOPE, 1998, p.10).

Assim, objetivamos realizar uma pesquisa exploratória bibliográfica através de levantamento das literaturas sobre a regulamentação/formação dos pedagogos, prosseguindo com entrevistas aos profissionais do Instituto de Educação da UFPA, estendendo ao Tribunal de Justiça do Estado do Pará, para a realização de estudo de caso com intuito de verificar a atuação dos pedagogos nesta instituição, através da aplicação de questionários e entrevistas, sem a pretensão de definir um perfil desses profissionais, mas de mostrar a atuação do pedagogo em um "novo território", tratando-se, portanto, de uma pesquisa qualitativa compreendida

sob duas perspectivas, primeiro por valorizar a ação do sujeito pesquisador no processo de análise e interpretação dos dados coletados; segundo como um tipo de pesquisa que, utilizando procedimentos próprios (entrevistas, observações, estudo de caso etc), reconhece a impossibilidade de métodos quantitativos revelarem a essência dos fenômenos. Assim, o adjetivo qualitativo é atributo de boas pesquisas, pois é indicativo da existência de um movimento de análise, da afirmação do elemento humano no processo de produção do conhecimento (ARAÚJO, 2010, p.14).

Ao nos lançarmos a pesquisar a regulamentação e a consequente atuação de pedagogos em ambientes não-escolares, enfocando o Poder Judiciário, através de uma pesquisa que visa discutir as normas e confrontá-las com a realidade da formação/atuação que exercemos, 
encontramos um grande desafio. Temos clareza dos riscos, mas também das possibilidades de dissipação dos limites a que essa temática por vezes pode ser encerrada.

\section{A regulamentação do curso de Pedagogia}

Colocar sob provisória suspeita os conceitos, referenciais teóricos, as práticas institucionais e pôr em suspenso (BUJES, 2007) o que Foucault denominou de "regimes de verdades", isto é, "os tipos de discurso que aceita e faz funcionar como verdadeiros; os mecanismos e instâncias que permitem distinguir entre sentenças verdadeiras e falsas, os meios pelos quais cada um deles é sancionado" (1993, apud BUJES, 2007, p. 24), é o desafio de enveredar nos questionamentos que provêm de leis que estão por normatizar os cursos de pedagogia e, por conseguinte, indicar a formação desses profissionais.

Para isso, é necessário entrar em campos de disputas e de distintas concepções a respeito da identidade e da organização do curso de pedagogia, num contexto de constantes avanços científico-tecnológicos produzidos ao longo da história da humanidade, tendo em vista o caráter evolutivo do campo de trabalho, especialmente na primeira década do século XXI.

A renovação dos conteúdos que perpassam os cursos de licenciatura se torna tarefa urgente, uma vez que o trabalho do profissional da pedagogia nos espaços pedagógicos é resultado concreto da trajetória escolar vivenciada na formação acadêmica, já que as diretrizes curriculares dos cursos de pedagogia são normatizadas com base na Resolução do $\mathrm{CNE} / \mathrm{CP} \mathrm{n}^{\mathrm{o}}$ 1/2006 e têm se preocupado com as atividades curricularesdisciplinares voltadas para a formação do docente.

O pressuposto desta investigação é analisar a regulamentação do curso de pedagogia com a consequente atuação deste profissional no Poder Judiciário paraense, uma vez que, apesar de ter prerrogativas que apoiam a atuação do pedagogo em áreas não-escolares - como a constante nos dois primeiros parágrafos da Resolução $N^{\circ}$ 2669/99² -, acabam não sendo

\footnotetext{
${ }^{2}$ Resolução do Colegiado do Curso de Pedagogia, que altera a Resolução No 1234/86CONSEP e define o Currículo do Curso de Licenciatura Plena em Pedagogia da Universidade Federal do Pará.
}

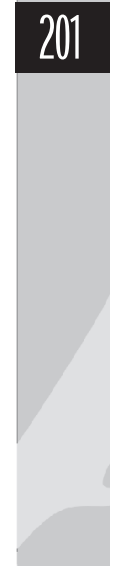


contempladas no desenho curricular do mesmo curso, ainda que conste no artigo $9^{\circ}$ da mesma resolução a seguinte norma: "O Núcleo Eletivo poderá compreender os tópicos temáticos: [...] formação e capacitação de profissionais em ambientes não-escolares", e que imediatamente deixam de ser observados nas atividades curriculares dos artigos seguintes, o que pode acabar favorecendo a ausência de disciplinas voltadas para uma ação pedagógica em ambientes não-escolares.

Em tais normatizações, o pedagogo deve ser capacitado e qualificado "para a construção dos processos educativos em seus diferentes espaços e dimensões [...] e para os diferentes campos de atuação profissional [...]". No entanto, se analisarmos os mais diversos desenhos curriculares do curso de pedagogia, como o da UFPA, no norte, e da Faculdade de Educação da UNICAMPI, do sudeste do país (que habilita o aluno a exercer o magistério de séries iniciais do ensino fundamental e médio), podemos visualizar que a ênfase das disciplinas é para a formação do pedagogo no âmbito escolar, mesmo nas disciplinas eletivas e/ou optativas.

Contudo, se fizermos uma busca nos últimos concursos públicos do estado do Pará, podemos perceber que vagas para o curso de pedagogia foram ofertadas nas mais diversas áreas:

- Junta Comercial do Estado do Pará (JUCEPA), Agência de Defesa Agropecuária do Estado do Pará (ADEPARÁ), Secretaria de Estado de Meio Ambiente (SEMA), Secretaria de Estado de Pesca e Aquicultura (SEPAq), Secretaria de Estado de Desenvolvimento, Ciência e Tecnologia (SEDECT), Secretaria de Estado de Justiça e Direitos Humanos (SEJUDH), Fundação Centro de Hematologia e Hemoterapia do Estado do Pará (HEMOPA/PA), Superintendência do Sistema Penitenciário do Estado - PA (SUSIPE), Secretaria Executiva de Estado de Cultura (SECULT), Secretaria Executiva de Estado de Ciência, Tecnologia e Meio Ambiente (SECTAM), Defensoria Pública do Estado do Pará, Empresa de Assistência Técnica e Extensão Rural do Estado do Pará (EMATER/ PARÁ), Departamento de Trânsito do Estado do Pará (DETRAN/PA), Banco da Amazônia S.A (BASA) e Tribunal de Justiça do Estado do Pará (TJ/PA). 
Demonstrando que a realidade da atuação do profissional da pedagogia hoje vai além do que a Associação Nacional pela Formação dos Profissionais da Educação (ANFOPE) preconiza, ou seja, a "docência como a base da formação profissional de todos aqueles que se dedicam ao estudo do trabalho pedagógico" (ANFOPE, 1998, p.10), pressuposto normatizado pelo CNE na Resolução no 1/2006.

Tal normatização para os cursos de pedagogia é considerada por Scheibe (2007) como "um parecer que não se refere ao pedagogo, mas à formação do licenciado em pedagogia”, e para Libâneo (2006) como sendo um "equívoco teórico", pois considera que:

O esfacelamento dos estudos no âmbito da ciência pedagógica e a consequente subjunção do especialista no docente, e a improcedente identificação dos estudos pedagógicos a uma licenciatura, talvez sejam dois dos mais expressivos equívocos teóricos e operacionais da legislação e do próprio movimento da reformulação dos cursos de formação do educador, no que se refere à formação do pedagogo (p. 115).

Tomar como objeto de análise as normatizações e regulamentações dos cursos de pedagogia, com vistas a discutir como as universidades formadoras do profissional da educação associam as leis em vigor para formar o pedagogo nas várias esferas do educativo para o enfrentamento dos desafios colocados pelas novas realidades do mundo contemporâneo (LIBÂNEO, 2006), poderá contribuir para a ampla discussão "que tornou-se um dos temas mais polêmicos dentre aqueles a serem regulamentados pela legislação complementar" (SCHEIBE, 2001), uma vez que compreendemos que não é necessariamente o "local" de trabalho do pedagogo, mas sim o conjunto de intenções e interesses contraditórios que compõem o processo de formação (inicial e contínua) do profissional (ANDRADE apud ARAÚJO, 2007, p. 200).

\section{Identidade do curso de Pedagogia}

Pedagogia, para Pimenta (2006), é a ciência que tem a prática social da educação como objeto de investigação e de exercício profissional, no 
qual se inclui a docência, embora nele se incluam outras atividades de educar. Complementarmente, Libâneo (2006) assinala que Pedagogia é, antes de tudo, um campo científico, não um curso, e esclarece que o curso que lhe corresponde é o que forma o "investigador da educação e o profissional que realiza tarefas educativas seja ele docente ou não diretamente docente" e enfatiza que:

$\mathrm{O}$ curso de Pedagogia não se reduz à formação de professores. Ou seja, todo trabalho docente é trabalho pedagógico, mas nem todo trabalho pedagógico é trabalho docente. O professor está no pedagogo, o pedagogo está no professor, mas cada profissional desses pede uma formação diferenciada. Disso decorre que a base da formação de educadores não é a docência, mas a formação pedagógica. A docência é uma das modalidades de trabalho pedagógico (LIBÂNEO, p.60-61, 2006).

Franco (2006) afirma que estamos há décadas derrapando na questão da especificidade das funções dos profissionais da educação, e não é neste trabalho que elas vão se encerrar.

Já Brzezinski (2000), atual presidente da ANFOPE, parte da proposta que deve haver a estimulação e articulação da "formação pedagógica com a formação específica das diversas áreas de saber que formam professores" (p. 228). Nesse sentido, a formação de professores nos cursos de pedagogia pode limitar a atuação do pedagogo à escola, indo na contramão da realidade de atuação desses profissionais nos dias atuais.

Dada essa complexidade sobre identidade/finalidade do curso de pedagogia, devemos nos atentar para "as novas determinações legais que não só extinguem diversas funções que cabiam, historicamente, ao curso de Pedagogia, mas, principalmente, colocam-se contra a multidimensionalidade intrínseca à sua natureza" (SILVA, 2001 apud SCHEIBE, 2002) e "compõem uma situação que pode gerar, gradativamente, a extinção do curso de pedagogia no Brasil" (SCHEIBE, 2002, não paginado).

Nesse sentido, será que a formação do profissional da educação em áreas não-escolares deverá ocorrer somente no nível de especialização? Ao formar especificamente o pedagogo docente não estaríamos recaindo 
em contradição com as posições históricas de luta pela articulação de todos os componentes curriculares da academia para superar as práticas curriculares que tradicionalmente dicotomizam teoria x prática, pensar $\mathrm{x}$ fazer, trabalho $\mathrm{x}$ estudo, pesquisa $\mathrm{x}$ ensino, já que a demanda para este profissional está saindo dos muros da escola?

Esse profissional atuante em área extraescolar é caracterizado por Libâneo (2007) como "pedagogo stricto sensu, isto é, um profissional não diretamente docente que lida com fatos, estruturas, processos, contextos, situações, referentes à prática educativa em suas várias modalidades e manifestações", atuando, assim, em ambiente extraescolar, como os pedagogos atuantes em varas ${ }^{3}$ cíveis e criminais no Tribunal de Justiça do Estado do Pará.

É com base nestes questionamentos que devemos estar atentos às leis que regulamentam a nossa formação, que implica na atuação, para reivindicarmos para o curso de pedagogia a formação de profissionais não só para Educação Básica, com formação docente vinculada à Educação Infantil e Séries Iniciais do Ensino Fundamental, mas também uma formação que contemple a atual demanda do trabalho com vistas à emancipação (MÉSZÁROS, 2008, p. 15), para não sermos instrumentos daqueles estigmas da sociedade capitalista que legitima os interesses dominantes.

\section{A atuação do pedagogo no Judiciário paraense}

É notório que nos encontramos diante de novas realidades onde a atuação do pedagogo vai além da docência. Assim, verificamos que é pertinente e de responsabilidade que as instituições de ensino superior revejam a formação dos profissionais da educação com as qualificações e o perfil que a sociedade do século XXI exige, uma vez que "a educação é, pois, compreendida como elemento constituído e constituinte crucial de luta de classes [...]. A luta é justamente para que a qualificação humana não seja subordinada às leis do mercado e à sua adaptabilidade $\mathrm{e}$ funcionalidade" (FRIGOTO, 2003, p. 21 e 31).

Neste contexto, pensar sobre a cultura, a diversidade, a pluralidade, a alteridade frente às relações de dominação e poder são decorrências

${ }^{3}$ Jurisdição 
quase que inalienáveis quando se enfatiza a atuação dos pedagogos no Judiciário paraense, que no primeiro certame público da sua história ofertou vagas para essa área e lotou a maioria dos pedagogos/pedagogas em Varas Cíveis e Criminais para atuarem diretamente em ações judiciais, de forma a subsidiar as decisões dos juízes e juízas, sejam em ações de guarda, alimentos, curatela, adoção, seja em crimes de ameaça, lesão corporal, homicídio ou em execução de penas, entre outras.

As lotações dos pedagogos a partir do ano de 2006 ocorreram em diversas Varas, entre cíveis e criminais, como por exemplo: Varas da Infância e Juventude, Varas de Família, Varas dos Juizados de Violência Doméstica e Familiar Contra a Mulher, Varas de Crimes Contra Crianças e Adolescentes, Vara de Execução Penal, Vara de Execução de Penas e Medidas Alternativas, entre outras.

Geralmente, nas lotações, era contemplada a constituição de uma tríade multidisciplinar, composta por psicólogo (a), assistente social e pedagogo (a), que tem como finalidade a garantia de direitos dos sujeitos usuários do sistema de justiça.

Os juízes (as), normalmente, solicitam um "estudo social", com base em legislações, como o Estatuto da Criança e Adolescente, o Código Civil, a Lei 11.340/06, popularmente conhecida como Lei Maria da Penha, que no Título V normatiza:

Compete à equipe de atendimento multidisciplinar, entre outras atribuições que lhe forem reservadas pela legislação local, fornecer subsídios por escrito ao juiz, ao Ministério Público e à Defensoria Pública, mediante laudos ou verbalmente em audiência, e desenvolver trabalhos de orientação, encaminhamento, prevenção e outras medidas, voltados para a ofendida, o agressor e os familiares, com especial atenção às crianças e aos adolescentes.

Diante dessa realidade, há que se questionar qual formação técnica o pedagogo possui para elaborar laudos voltados para o campo jurídico ${ }^{4}$,

${ }^{4}$ Campo (ou sistema) sócio-jurídico diz respeito ao conjunto de áreas em que a ação do Serviço Social articula-se a ações de natureza jurídica como o sistema Judiciário, o sistema penitenciário, o sistema de segurança, os sistemas de proteção e acolhimento como abrigos, conselhos de direitos, entre outros (Conselho Federal de Serviço Social). 
uma vez que, assim como o conhecimento das leis, o profissional deve possuir instrumentais para elaborar estudos de caso, laudos, pareceres, avaliações, de acordo com as necessidades do juízo e até mesmo realizar perícias ou ser assistente técnico em determinados processos. Nesse lócus, assim como é nova a atuação de pedagogos nessas áreas, também o é a limitação para o exercício das funções diante das próprias solicitações destinadas a eles, já que, no momento em que é solicitado um "estudo social" ao pedagogo, pode-se estar incorrendo em imperícia, pois tais instrumentos são de especificidade do Serviço Social (Conselho Federal de Serviço Social, 2006, p. 10).

Nesse sentido, os psicólogos podem utilizar o "Relatório Psicológico". Os assistentes sociais, o "Estudo Social", já os pedagogos, aparentemente, ainda não construíram, consolidaram e institucionalizaram um instrumental técnico que referende tal atuação.

Será que é possível, no curso de pedagogia, a aprendizagem de instrumentais técnicos para utilização em áreas que não sejam a escolar e aí se incluem: relatórios de atividades, de atendimentos, coleta e análise de dados, diagnoses, elaboração de laudos e pareceres? Uma vez que as próprias Diretrizes Curriculares Nacionais para o Curso de Pedagogia, em seu artigo $5^{\circ}$, inciso XV contemplam que os pedagogos devem: "utilizar, com propriedade, instrumentos próprios para construção de conhecimentos pedagógicos e científicos" (grifos nossos), evidenciandose, nesta perspectiva, para além da dimensão instrumental, que a formação do profissional da educação deve incluir estudos sistemáticos e avançados no campo da educação, como forma de responder adequadamente aos desafios que ora se apresentam.

Esse viés investigativo pode possibilitar a ampliação das discussões que se ocupam das questões de práticas formativas em educação superior no Pará, não só para assentar uma necessidade emergente em formar especialistas numa área que tem de articular de forma sólida os saberes não-escolares - como o do Direito e das Ciências Humanas, concretizados nos serviços de assessoria técnica aos Tribunais, no apoio às decisões dos magistrados -, mas também para orientar e propor ações de formação que visem à qualificação do trabalhador com as competências necessárias para a intervenção em áreas complementares, em meio institucional ou comunitário, com ênfase na formação emancipadora, para formar

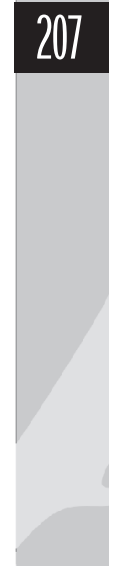


profissionais com bases necessárias a um posicionamento crítico e uma compreensão dialética dos fenômenos que ocorrem no interior de cada unidade produtiva (ARAÚJO, 2007).

Partindo destes questionamentos, esta pesquisa implica não só na identificação de dados correlacionados a estas questões, frente aos mecanismos de motivação intrínsecos e extrínsecos, coletivos e individuais, envolvidos na ação ou intenção de compreender, de forma mais profunda, o conhecimento pedagógico para que ele possa ser melhor disponibilizado, compartilhado e socializado, de forma a gerar um novo modelo de formação dos profissionais da pedagogia, mas também em rever as normatizações educacionais e sócio-educacionais constantes nas legislações que regulam os cursos de pedagogia.

Será que tais paradigmas implicam também num paradoxo, e de maneira oposta, estariam relacionados à existência de alguns modelos, de algumas políticas públicas e fazeres institucionais educacionais e sócioeducacionais geradores de reprodutivismos?

\section{Considerações não-conclusivas}

A pesquisa, em fase inicial, da qual este texto é resultante, se constitui em uma continuidade dos estudos sobre o curso de pedagogia, enfatizando a atuação de pedagogos no mercado de trabalho diverso do escolar, abordando um lócus novo, isto é, o Tribunal de Justiça do Estado do Pará.

A partir das interrogações provenientes das perguntas sobre a atuação do pedagogo em ambiente não-escolar, devemos nos atentar para as políticas públicas educacionais de formação dos pedagogos, não visando a adequação aos interesses pragmáticos do capital; numa perspectiva utilitária de habilitação e treinamento, estando a serviço exclusivo do mercado de trabalho, mas sim investigando as propostas de ações que contribuam para a humanização plena do profissional, através de "formação emancipadora, que possa oferecer as bases necessárias para um posicionamento crítico e uma compreensão dialética dos fenômenos que ocorrem no interior da unidade produtiva" (ARAÚJO, 2007, p. 198). 
Construir um objeto de investigação é, sobretudo, expô-lo em suas condições mais amplas de emergência, situando-o em relação a outros conjuntos ou objetos similares. A preocupação, portanto, será não tomar os objetos "em si" como objetos naturais e dados, deslocados do espaço social, político e cultural mais amplo, como se fossem entidades com vôo próprio, mas o tratarmos efetivamente como objetos históricos que são (ARAÚJO, 2007).

Perceber a mudança no cenário de trabalho e assumir políticas educacionais nos cursos de pedagogia com vistas a não só formar os profissionais para responder a uma demanda do mercado trabalho, mas para assegurar o reconhecimento do "contexto histórico-social em que o trabalho se realiza. Uma educação que se volte para a ampliação dos horizontes de conhecimentos, atentando para os determinantes sociais, econômicos e políticos das situações de vida" (ARAÚJO, 2007, p. 198), são as questões norteadoras da pesquisa.

Assim, este artigo teve como propósito colocar algumas questões, como: presença do pedagogo em ambiente não-escolar, limites da formação técnica, currículo do curso de pedagogia, partindo do contraponto regulamentação $\rightarrow$ formação $\rightarrow$ atuação, com enfoque no Judiciário paraense.

\section{REFERÊNCIAS}

ARAÚJO, Ronaldo Marcos de Lima. et. al. A Educação profissional no Pará. Belém: EDUFPA, 2007.

O marxismo e a pesquisa qualitativa como referências para investigação sobre educação profissional. In: Seminário do Trabalho da RET - Rede de Estudos do Trabalho, VII, 2010, Marília/SP. Anais. Marília: UNESP, 2010.

Associação Nacional pela Formação dos Profissionais da Educação/ ANFOPE. Documento final do $\mathbf{9}^{\circ}$ Encontro Nacional. Brasília, 1998.

- Associação Nacional de Pós-Graduação e Pesquisa em Educação/ANPEd, Centro de Estudos Educação e Sociedade/CEDES. A definição das diretrizes para o curso de pedagogia. Rio de Janeiro, 
set./2004. Disponível em: <http//www.anped.org.br/memoria/2004/ PosicaoDiretrizescursosPedagogia.doc $>$. Acesso em 20/05/2010.

BRASIL, Conselho Nacional de Educação. Resolução n. 1/2006. Brasília/DF, 15/05/2006, Seção 1, p. 11. Disponível em: < http://portal. mec.gov.br/cne/arquivos/pdf/rcp01 06.pdf >. Acesso em: 07/07/2009.

BRASIL. Conselho Federal De Serviço Social. O Estudo Social em perícias, laudos e pareceres técnicos: contribuição ao debate no Judiciário, no penitenciário e na previdência social. São Paulo: Cortez, 2006.

BRASIL. Lei n. 9.394/96, de 20/12/1996. Estabelece as diretrizes e bases para a educação nacional. Diário Oficial da União. Brasília: Gráfica do Senado, v. 134, n.1.248, 23/12/1996. Disponível em: < http://www. planalto.gov.br/ccivil 03/Leis/L9394.htm > . Acesso: 12/07/2009.

BRZEZINSKI, Iria. Pedagogia, pedagogos e formação de professores. Campinas: Papirus, 2000.

BUJES, Maria Izabel E. Descaminhos. In: COSTA, M. V. (Org.). Caminhos Investigativos II: outros modos de pensar e fazer pesquisa em educação. Rio de Janeiro: Lamparina, 2007.

FISCHER, Rosa M. B. Verdades em suspenso: Foucault e os perigos a enfrentar. In: COSTA, M. V. (Org.). Caminhos Investigativos II: outros modos de pensar e fazer pesquisa em educação. Rio de Janeiro: Lamparina editora, 2007.

FRANCO, Maria Amélia S. Para um currículo de formação de pedagogos. In: PIMENTA, S. G (Org.). Pedagogia e Pedagogos: caminhos e perspectivas. São Paulo: Cortez, 2006.

210 FRIGOTTO, G. Educação e crise do capitalismo real. $8^{a} \mathrm{Ed}$. Petrópoles: Vozes, 2006.

LIBÂNEO, José Carlos. Ainda as perguntas: o que é pedagogia, quem é o pedagogo, o que deve ser o curso de Pedagogia. In: PIMENTA, S. G (Org.). Pedagogia e Pedagogos: caminhos e perspectivas. São Paulo: Cortez, 2006.

Que destino os educadores darão à Pedagogia? In: PIMENTA, S. G (Org.). Pedagogia, ciência da educação? São Paulo: Cortez, 2005. 
Pedagogia, Ciência da Educação? In: PIMENTA, S. G (Org.).

Pedagogia, ciência da educação? São Paulo: Cortez, 1996, p. 127.

PIMENTA, Selma Garrido. Formação dos profissionais da educação: visão crítica e perspectivas de mudança. In: Pimenta, S. G (Org.). Pedagogia e Pedagogos: caminhos e perspectivas. São Paulo: Cortez, 2006.

MÉSZÁROS, István. Educação para além do capital. São Paulo: Boitempo, 2008.

PARÁ. Edital n. 01, de $1^{\circ}$ de março de 2006. Diário de Justiça do Estado do Pará, Belém/PA, 01/mar/2006.

PIRES, Marília Freitas de Campos. O materialismo históricodialético e a Educação. Paradigmas de Interpretação da Realidade e Projetos Pedagógicos. Botucatu, 1997.

PARÁ. Universidade Federal do Pará, Colegiado do Curso de Pedagogia. Resolução n. 2669/99. Belém/PA, 1999. Disponível em: < http://www. cultura.ufpa.br/pedagogia/

resol_2669.htm> Acesso em: 10/06/2009.

SCHEIBE, Leda. Diretrizes curriculares para o curso de Pedagogia: trajetória longa e inconclusa. Cadernos de Pesquisa. Santa Catarina, 2007.

Pedagogia e sua multidimensionalidade: Diferentes olhares. A contribuição da ANFOPE para a compreensão da formação do Pedagogo no Brasil. Disponível em: < http://www.anped.org.br/ reunioes/24/ts1.doc >. Acesso em: 14/05/2010. 